\title{
BMJ Open Sexual harassment and organisational silencing in nursing: a cross-sectional study in Greece
}

\author{
Panagiotis Papantoniou
}

To cite: Papantoniou P. Sexual harassment and organisational silencing in nursing: a cross-sectional study in Greece. BMJ Open 2021;11:e050850. doi:10.1136/ bmjopen-2021-050850

- Prepublication history and additional supplemental material for this paper are available online. To view these files, please visit the journal online. (http://dx.doi.org/10.1136/ bmjopen-2021-050850).

Received 06 March 2021 Accepted 06 August 2021
Check for updates

(C) Author(s) (or their employer(s)) 2021. Re-use permitted under CC BY-NC. No commercial re-use. See rights and permissions. Published by BMJ.

Business School, The University of Warwick, Coventry, UK

Correspondence to Panagiotis Papantoniou; phd19pp@mail.wbs.ac.uk

\section{ABSTRACT}

Objective This study investigates the frequency of sexual harassment among female nurses in the Greek health system and the nurses' reluctance to report their experiences.

Design Cross-sectional study.

Setting Greece.

Participants 1264 female nurses of working age across different settings responded to the Sexual Experiences Questionnaire (SEQ) web-based format between October 2020 and February 2021. The period investigated by the SEQ was the participant's entire professional life. The final sample consisted of 1217 nurses with valid data on the frequency of sexually harassing behaviours (gender harassment, unwanted sexual attention, sexual coercion) and the reasons for not reporting sexual harassment. Main outcome measures The frequency of sexual harassment was measured in a 5-point Likert Scale (1: very often, 2: often, 3: occasionally, 4: rarely, 5: never), the decision to report/not report sexual harassment was measured in a yes/no format and the impact of sexual harassment on the physical, mental and job-related performance was measured in a 5-point Likert Scale (1: very positively, 2: positively, 3: moderately, 4: negatively, 5: very negatively).

Results $70 \%$ of the nurses have experienced sexual harassment at least once in their working lives, while the most frequent type is gender harassment. Male doctors are the most common perpetrators. T-tests and analysis of variance showed that private and younger nurses were more likely to experience sexual harassment while divorced nurses with $1-5$ years of experience dealt with sexually coercive behaviours more frequently. $30 \%$ did not report sexual harassment because of the fear of negative consequences and beliefs that no action will be taken against the perpetrator. Multiple regression analyses showed that unwanted sexual attention and sexual coercion explain the victim's physical and job-related adverse outcomes. Cronbach's $\alpha$ was 0.939 .

Conclusions The results show that sexual harassment rates are high in the Greek health system, while many victims do not report their experiences to the authorities. This emphasises the need to implement drastic measures on behalf of the National Health Service (NHS) policy makers towards helping victims speak up without the fear of negative consequences. Nurse managers are called to implement effective policies against sexual harassment.

\section{Strengths and limitations of this study}

Large representative sample of 1264 female nurses.

- Explored the prevalence of the three types of sexual harassment: gender harassment, unwanted sexual attention and sexual coercion and victim's reasons for not reporting their experiences.

- Limitations of this study include the relative low response rate $(20 \%)$, that no male nurses were examined and that responses may be influenced by recall bias.

\section{INTRODUCTION}

The \#MeToo and Time's Up movements have put a global spotlight on the phenomenon of sexual harassment. ${ }^{1}$ According to the US Equal Employment Opportunity Commission (2010), sexual harassment is any unwelcome sexual advances, requests for sexual favours, and other verbal or physical conduct of a sexual nature that explicitly or implicitly affects an individual's employment or creates an intimidating, hostile or offensive work environment'. ${ }^{2}$ Researchers that conceptualise sexual harassment behaviourally have articulated that sexual harassment has three broad categories; gender harassment, unwanted sexual attention and sexual coercion. ${ }^{3}$ Due to differences in the definitions of sexual harassment and the various tools used to measure it, studies exploring the prevalence of sexual harassment show large discrepancies. According to a survey of the European Union Agency for Fundamental Rights, an estimated $45 \%-55 \%$ of women in the 28 European Union Member States have experienced sexual harassment since the age of 15 years. ${ }^{4}$ Another study by the United Nations (2016) has found that more than $35 \%$ of women globally have experienced sexual harassment once in their lives. ${ }^{5}$ If we look at the healthcare industry, a study has shown that health professionals are 16 times more likely to experience workplace violence than other working groups. ${ }^{6}$ As for the 
prevalence of sexual harassment among female nurses, a recent systematic review that synthesised data from 189 studies showed that the prevalence ranged from $10 \%$ to almost $90 \%$, while $35 \%$ of female nurses faced verbal sexual harassment, whereas $31 \%$ of them experienced sexual harassment in the form of unwanted touching, attempts to rape and sexual assault. ${ }^{7}$

Even in the Greek National Health Service (NHS) context, a study has shown that more than $60 \%$ of female nurses had experienced at least one form of violence at work. ${ }^{8}$ As for the perpetrators, the literature shows that patients, patients' family members, physicians and co-workers are the most frequent sexual harassers. ${ }^{9-11}$

Unsurprisingly, sexual harassment has various negative job-related, mental and physical consequences for victims. Studies have revealed that sexual harassment decreases job satisfaction, ${ }^{12}$ organisational commitment, ${ }^{13}$ productivity and performance, ${ }^{14}$ and increases stress, ${ }^{15}$ turnover, ${ }^{16}$ burn-out. ${ }^{17}$ Other research papers have revealed that sexual harassment hurts interpersonal relationships between employees, showing the workplace's broader jobrelated implications. ${ }^{18}$ As for the psychological outcomes, the most common are depression, stress, avoidance, changes in arousal, hypervigilance and psychological burn-out. ${ }^{19-21}$ As for the physical consequences, articles have shown that victims deal with headaches, exhaustion, dizziness, gastrointestinal issues, nausea, sleep difficulties, menstrual disturbances and muscular pain. ${ }^{722}{ }^{23}$ Sexual harassment has also been found to be associated with suicidal behaviour. ${ }^{1}$

The above shows that sexual harassment is a frequent phenomenon in healthcare that causes several negative consequences. Similar studies have focused on exploring the frequency of sexual harassment among nurses without clearly identifying the most common types of sexual harassment. At the same time, studies in sexual harassment have not looked explicitly at whether victims speak up about their experiences and, if they don't, why they do so. Additionally, research articles have shown that female nurses compared with male nurses disproportionally deal with sexual harassment in clinical settings, with figures showing an increasing trend. ${ }^{23}$ This study aims at filling this crucial gap and exploring the prevalence of sexual harassment of female nurses in the Greek NHS and the frequency of reporting/not reporting sexual harassment.

To our knowledge, this is the first study that explicitly looks at why sexual harassment victims do not report their experiences in the context of healthcare. To rectify this, we did a cross-sectional survey on sexual harassment using the Sexual Experiences Questionnaire (SEQ) that is the most reliable tool to measure sexual harassment in a large sample of Greek female nurses.

\section{METHODS}

\section{Study design and setting}

This is a cross-sectional electronic survey developed using Qualtrics adopting convenience sampling. Data collection took place for 4 months from October 2020 to February 2021 across female nurses working in public and private settings, including hospitals, health centres, and other health facilities in Greece. The reason for adopting convenience sampling was because this study was conducted during the COVID-19 pandemic in Greece; hence this sampling strategy would ensure a representative sample of participants during these disruptive times. The online survey was uploaded to the official Facebook page of the Hellenic Association of nurses. The survey link was also forwarded through email to potential participants through professional Facebook pages on nursing in Greece. The participants were requested to forward the link of the study to as many female nurses as possible. Hence, the link of the e-survey was rolled out to female nurses apart from the first point of contact. On clicking on the link, participants were auto-directed to the first page of the survey that included the researcher's information, the purpose of the study and how researchers would process the data. Participation in this study was entirely voluntary while to proceed to the part of the questions, participants were asked to give their consent and confirm that they allow their data to be analysed for research purposes. It was also stated that the filling of the survey would take approximately $15 \mathrm{~min}$ and that all data would be stored at the University's safe research drive for 5 years. We used three evidence-based ways to increase the response rate of our electronic surveys. ${ }^{24}$ First, we used various online channels to reach more female nurses that would be interested in participating in the study. Second, we posted three messages on the professional Facebook page of the Hellenic Association of nurses throughout the data collection period to motivate nurses to participate in the online survey and third female representatives of the association were contacted to ask them to encourage more female nurses to fill the questionnaire. To prevent respondents from taking the survey more than once, we enabled 'Prevent Ballot box stuffing' from Qualtrics, which prevents people with the same IP to fill the online questionnaire many times. The link was accessed by 6102 female nurses, of which 1219 agreed to participate and completed the questionnaire, that is a response rate of $20 \%$.

\section{Specific objectives}

1. To investigate the prevalence of sexual harassment of female nurses.

2. To determine the most frequent types of sexual harassment experienced by female nurses.

3. To examine whether sociodemographic data (age, marital status, employment sector, years of work experience) had an association with the frequency of sexual harassment.

4. To investigate the reasons why sexually harassed victims do not report sexual harassment. 


\section{Study population}

The population of this study was female nurses currently working in the Greek health sector. The inclusion criteria for participating in the study were: (1) Being more than 18 years old, (2) Have a nursing degree, (3) Enrolled in the Hellenic Nurses Association. The exclusion criteria were: (1) Not currently working in the Greek health sector, (2) Not having a degree in nursing, (3) Not female nurses.

\section{Sample size calculation}

We used the following formula to calculate the sample size $\mathrm{n}$ from a known population of female nurses

$\mathrm{n}=(\mathrm{z}) 2 \mathrm{p}(1-\mathrm{p})$

$\mathrm{n}=$ sample size

$\mathrm{z}=$ level of confidence at $95 \%$ (1.96)

$\mathrm{p}=$ expected prevalence of sexual harassment $(0.30)$

Margin error $=5 \%$.

Based on the calculation, this study's sample size should have been 379 female nurses. However, due to the sampling strategy adopted, the number of participants crucially increased to 1219 female nurses.

\section{Sexual harassment measures}

Sexual harassment was assessed using the $\mathrm{SEQ}^{325}$ (online supplemental appendix 1) that is considered the most reliable tool to explore sexual harassment. The SEQ follows a three-factor structure with a total of 22 questions that explore the frequency of gender harassment, unwanted sexual attention and sexual coercion. The first section included the study purpose, researchers' contact details and informed consent that needed to be signed before moving to the following parts of the survey. The second part asked about respondents' information such as gender, age, education, employment and years of work experience. The third part included questions measured on a 5-point Likert Scale (1: very often, 2: often, 3: occasionally, 4: rarely, 5: never) to describe how often male nurses experienced sexual harassment. Participants were presented with the following question: 'While working as a nurse, how often have you been in a situation where someone has:' and then questions appeared. The fourth and final part included three multiple-choice questions investigating the type of wrongdoer (male doctor, male nurse, female doctor, female nurse, visitor, patient), the place where sexual harassment occurred and the main reasons why victims did not report their experiences. There were also two questions measured in a binary format (Yes/No) that examined whether victims reported their experiences as well as whether the hospital conducted an internal investigation. These questions were asked to achieve a holistic understanding of the participants' experiences with sexual harassment in healthcare settings and understand how hospitals dealt with victims' complaints. The SEQ was first translated in Greek, distributed in the Greek language and then all responses were translated back to English for analysis.

\section{Data analysis}

We used the Statistical Package for Social Sciences V.27. First, the questionnaire's internal consistency was tested using Cronbach's $\alpha$, aiming for a score of above $0.85 .{ }^{26}$ Descriptive statistics were used to describe our sample's characteristics. All scale variables were examined for normality using the Shapiro-Wilk test. Then, t-tests were conducted between the employment sector and continuous variables. One-way analysis of variance (ANOVA) was used to analyse the relationship between ordinal variables (work experience, age group, education) with scale variables. Last, multiple regression analysis was performed to investigate which sexually harassing behaviours were associated with the participants' negative physical, mental and job-related outcomes. A value of $\mathrm{p}<0.05$ was considered statistically significant.

\section{Patient and public involvement \\ No patient was involved.}

\section{RESULTS}

\section{Demographic characteristics of the sample}

As seen in table 1 , most female nurses worked in the public sector $(76 \%)$, belonged to the $18-30$ years $(38 \%)$ age group, held a degree from a technological educational institute $(40 \%)$, while more than a third had a postgraduate degree. One in two nurses was unmarried, and $40 \%$ of them had up to 5 years of work experience.

\section{Prevalence of sexual harassment}

Table 2 shows the frequencies of sexually harassing behaviours experienced by nurses. Almost 7 in 10 nurses have experienced sexual harassment at least once in their working lives (1478/22). The most frequent type of sexual harassment is gender harassment, with one in four nurses frequently experiencing such behaviours. Unwanted sexual attention is less frequent, with more than $60 \%$ experiencing such actions occasionally or rarely. Sexual coercion is the least regular type of sexual harassment, with $80 \%$ never facing such behaviours at work.

\section{Perpetrators of sexual harassment}

As for the perpetrators, in half of the cases, male doctors were the sexual harassers, followed by patients $(16.4 \%)$, male nurses $(10 \%)$ and male colleagues who are not doctors or nurses. Most cases occurred in inpatient care units $(30 \%)$, in the hallway (25\%) and the medical office of the perpetrators $(20 \%)$. Most times, sexual harassment victims adopted passive coping strategies $(55 \%)$, whereas a considerable proportion decided to stay silent (30\%). In the cases where victims reported the incident, the organisation did not conduct an internal investigation $(96 \%)$, whereas when it did, in most times, no action was taken against the perpetrator $(80 \%)$.

\section{Reasons for staying silent}

As for the victim's decision to stay silent, the main reasons can be categorised into three broad categories; the first 


\begin{tabular}{|c|c|c|}
\hline Variables & $\begin{array}{l}\text { Sample } \\
(n=1219)\end{array}$ & $\begin{array}{l}\text { Percentage } \\
(\%)\end{array}$ \\
\hline \multicolumn{3}{|l|}{ Age, years } \\
\hline $18-30$ & 463 & 38 \\
\hline $31-40$ & 395 & 32.4 \\
\hline $41-50$ & 306 & 25.1 \\
\hline $51-60$ & 55 & 4.5 \\
\hline \multicolumn{3}{|l|}{ Educational level } \\
\hline Secondary education & 64 & 5.3 \\
\hline Vocational training & 67 & 5.5 \\
\hline Technological education & 482 & 39.5 \\
\hline University education & 166 & 13.6 \\
\hline Master's & 420 & 34.5 \\
\hline PhD & 20 & 1.6 \\
\hline \multicolumn{3}{|l|}{ Employment sector } \\
\hline Public & 929 & 76.5 \\
\hline Private & 286 & 23.5 \\
\hline \multicolumn{3}{|l|}{ Work experience } \\
\hline Less than a year & 124 & 10.2 \\
\hline $1-5$ years & 366 & 30 \\
\hline $6-10$ years & 159 & 13 \\
\hline $11-16$ years & 294 & 24.1 \\
\hline $16+$ years & 276 & 22.6 \\
\hline \multicolumn{3}{|l|}{ Marital status } \\
\hline Married & 459 & 37.8 \\
\hline Unmarried & 615 & 50.7 \\
\hline Divorced & 140 & 11.7 \\
\hline
\end{tabular}

concerns the victim's beliefs that no action will be taken against the perpetrator (futility), the second discusses the fear of being negatively labelled by colleagues, fear of retaliation and fear of damaging the relationships with superiors $(35 \%)$ and the third relates to a lack of support from the organisation in terms of mechanisms to allow victims report their experiences and the lack of transparency and confidentiality of the procedures.

Moreover, nurses were asked whether they broke their silence at a later time. Interestingly, the findings show that 9 in 10 nurses did not break their silence, while those who decided to speak up did so because another victim broke her silence and that helped them do the same (35\%), because they received support from actors outside the organisation (30\%), to protect other 'potential' victims (prosocial motives) (20\%) and to retaliate to the perpetrator $(15 \%)$.

\section{Negative consequences of sexual harassment}

Of the sexual harassment victims, 30\% experienced physical problems, with the most frequent issues being headache, gastrointestinal tract diseases and sleep difficulties. One in two nurses dealt with mental issues due to sexual harassment, with anxiety, emotional exhaustion and depression being the most common problems. Lastly, $20 \%$ of the respondents reported that their ability to do their job was negatively affected, with difficulties in concentration, low job satisfaction, decreased productivity and unnecessary sick leaves being the most frequent job-related issues faced by victims.

\section{Private nurses more frequently deal with sexual harassment}

T-tests showed that private nurses compared with public nurses more frequently experienced sexist remarks, sexist jokes, crude and offensive sexual comments, gestures of sexual nature, unwanted asking for dates despite their refusal and quid pro quo sexual harassment. On the contrary, public nurses compared with private nurses were more frequently called or hooted sexually and dealt with unwanted attempts for sex without their consent.

\section{Younger nurses more often experience sexual harassment}

ANOVA between nurses' age group and sexual harassment behaviours showed statistically significant differences that were particularly evident when comparing the 18-30 years and 31-40 years age groups with all other age groups. Post hoc test Fisher's Least Significant Difference (LSD) showed that the younger the nurses, the more frequent sexual harassment behaviours were.

\section{Unmarried and divorced nurses experience more frequent sexual harassment}

ANOVA between nurses' marital status and sexual harassment behaviours showed statistically significant differences that were particularly evident when comparing unmarried and divorced nurses with all other groups. Post hoc test (LSD) showed that unmarried and divorced nurses more frequently experienced gender harassment and unwanted sexual attention behaviours, whereas divorced nurses often faced sexually coercive behaviours at work.

Nurses with limited years of experience and lower educational backgrounds more frequently experience sexual harassment

ANOVA between nurses' years of experience and sexual harassment behaviours showed statistically significant differences that were particularly evident when comparing nurses with 11-16 years and $<1$ year of experience with all other groups. Post hoc test (LSD) showed that those with 11-16 years of experience more often experienced gender harassment, those with less than a year more often faced unwanted sexual attention and those with 1-5 years of experience more frequently encountered sexually coercive behaviours. ANOVA between the nurses' academic level and sexual harassment behaviours in most tests did not show statistically significant differences. However, three post hoc tests (LSD) showed that those nurses with lower educational levels (ie, vocational training and secondary education) more frequently experienced sexist remarks compared with nurses with higher academic degrees, in the workplace. 
Table 2 Prevalence of sexual harassment

\begin{tabular}{|c|c|c|c|c|c|c|}
\hline Variables & $\begin{array}{l}\text { Very often } \\
(\mathrm{n}, \%)\end{array}$ & $\begin{array}{l}\text { Often } \\
(\mathrm{n}, \%)\end{array}$ & $\begin{array}{l}\text { Occasionally } \\
\text { (n, \%) }\end{array}$ & $\begin{array}{l}\text { Rarely } \\
(\mathrm{n}, \%)\end{array}$ & $\begin{array}{l}\text { Never } \\
(\mathrm{n}, \%)\end{array}$ & $\begin{array}{l}\text { Frequency } \\
(\%)\end{array}$ \\
\hline \multicolumn{7}{|l|}{ Gender harassment } \\
\hline $\begin{array}{l}\text { Has treated you differently because } \\
\text { of your sex }\end{array}$ & $176(14.4)$ & $413(33.9)$ & $387(31.7)$ & $185(15.2)$ & $58(4.8)$ & 95.2 \\
\hline $\begin{array}{l}\text { Displayed, used or distributed } \\
\text { sexist or suggestive materials }\end{array}$ & $55(4.5)$ & $198(16.2)$ & $711(58.3)$ & $237(19.4)$ & $18(1.5)$ & 98.5 \\
\hline Made offensive sexist remarks & $124(10.2)$ & $287(23.5)$ & $403(33.1)$ & $368(30.2)$ & $37(3)$ & 97 \\
\hline $\begin{array}{l}\text { Put you down or was } \\
\text { condescending to you because of } \\
\text { your sex }\end{array}$ & $119(9.8)$ & $337(27.6)$ & $384(31.5)$ & $347(28.5)$ & $32(2.6)$ & 97.4 \\
\hline \multicolumn{7}{|l|}{ Unwanted sexual attention } \\
\hline $\begin{array}{l}\text { Repeatedly told sexual stories or } \\
\text { jokes that were offensive to you }\end{array}$ & $147(12.1)$ & $383(31.5)$ & $317(26.1)$ & $311(25.6)$ & $56(4.6)$ & 95.4 \\
\hline $\begin{array}{l}\text { Whistled, called or hooted at you in } \\
\text { a sexual way }\end{array}$ & $32(2.6)$ & $349(28.6)$ & $444(36.4)$ & $368(30.2)$ & $22(1.8)$ & 98.2 \\
\hline $\begin{array}{l}\text { Made unwelcome attempts to draw } \\
\text { you into a discussion of sexual } \\
\text { matters }\end{array}$ & $69(5.7)$ & 352 (28.9) & $362(29.7)$ & $410(33.6)$ & $26(2.1)$ & 97.9 \\
\hline $\begin{array}{l}\text { Made crude and offensive sexual } \\
\text { remarks, either publicly or privately }\end{array}$ & $88(7.2)$ & $271(22.2)$ & $427(35)$ & $412(33.8)$ & $17(1.4)$ & 98.6 \\
\hline $\begin{array}{l}\text { Made offensive remarks about } \\
\text { your appearance, body or sexual } \\
\text { activities }\end{array}$ & $62(5.1)$ & $278(22.8)$ & $411(33.7)$ & $429(35.2)$ & $39(3.2)$ & 96.8 \\
\hline $\begin{array}{l}\text { Made gestures or used body } \\
\text { language of a sexual nature which } \\
\text { embarrassed or offended you }\end{array}$ & $38(3.1)$ & $244(20)$ & $468(38.4)$ & 455 (37.3) & $14(1.1)$ & 98.9 \\
\hline $\begin{array}{l}\text { Stared, leered or ogled at you } \\
\text { in a way that made you feel } \\
\text { uncomfortable }\end{array}$ & $102(8.4)$ & $437(35.8)$ & $400(32.8)$ & $224(18.4)$ & $56(4.6)$ & 95.4 \\
\hline $\begin{array}{l}\text { Has he made unwanted attempts } \\
\text { to establish a romantic sexual } \\
\text { relationship with you despite your } \\
\text { efforts to discourage it? }\end{array}$ & $27(2.2)$ & 198 (16.2) & $313(25.7)$ & $654(53.7)$ & $27(2.2)$ & 97.8 \\
\hline $\begin{array}{l}\text { Continued to ask you for dates, } \\
\text { drinks, dinner and so on, even } \\
\text { though you said "No" }\end{array}$ & $40(3.3)$ & $176(14.4)$ & $32(2.6)$ & $664(54.5)$ & 307 (25.2) & 74.8 \\
\hline $\begin{array}{l}\text { Touched you in a way that made } \\
\text { you feel uncomfortable }\end{array}$ & $19(1.6)$ & $226(18.5)$ & 422 (34.6) & $540(44.3)$ & $12(1)$ & 99 \\
\hline \multicolumn{7}{|l|}{ Sexual coercion } \\
\hline $\begin{array}{l}\text { Made unwanted attempts to stroke, } \\
\text { fondle or kiss you }\end{array}$ & $8(0.7)$ & $21(1.7)$ & 139 (11.4) & $303(24.9)$ & $748(61.4)$ & 38.6 \\
\hline $\begin{array}{l}\text { Attempted to have sex with you } \\
\text { without your consent or against } \\
\text { your will, but was unsuccessful }\end{array}$ & $0(0)$ & $4(0.3)$ & $37(3)$ & $45(3.7)$ & $1133(92.9)$ & 7.1 \\
\hline $\begin{array}{l}\text { Had sex with you without your } \\
\text { consent or against your will }\end{array}$ & $0(0)$ & $0(0)$ & $4(0.3)$ & $10(0.8)$ & 1205 (98.9) & 1.1 \\
\hline $\begin{array}{l}\text { It made you feel like you were being } \\
\text { bribed with some reward or special } \\
\text { treatment to engage in sexual } \\
\text { behaviour }\end{array}$ & $0(0)$ & $25(2.1)$ & $87(7.1)$ & $108(8.9)$ & 996 (81.9) & 18.1 \\
\hline $\begin{array}{l}\text { It made you feel threatened with } \\
\text { some retaliation for not being } \\
\text { sexually cooperative }\end{array}$ & $13(1.1)$ & $13(1.1)$ & $50(4.1)$ & $122(10)$ & $1018(83.7)$ & 16.3 \\
\hline
\end{tabular}




\begin{tabular}{|c|c|c|c|c|c|c|}
\hline Variables & $\begin{array}{l}\text { Very often } \\
(n, \%)\end{array}$ & $\begin{array}{l}\text { Often } \\
(n, \%)\end{array}$ & $\begin{array}{l}\text { Occasionally } \\
(n, \%)\end{array}$ & $\begin{array}{l}\text { Rarely } \\
(n, \%)\end{array}$ & $\begin{array}{l}\text { Never } \\
(n, \%)\end{array}$ & $\begin{array}{l}\text { Frequency } \\
(\%)\end{array}$ \\
\hline $\begin{array}{l}\text { Implied faster promotions or better } \\
\text { treatment if you were sexually } \\
\text { cooperative }\end{array}$ & $13(1.1)$ & $18(1.5)$ & $94(7.7)$ & 149 (12.2) & 942 (77.3) & 22.7 \\
\hline $\begin{array}{l}\text { It made you afraid you would } \\
\text { be treated poorly if you didn't } \\
\text { cooperate sexually }\end{array}$ & $9(0.7)$ & $13(1.1)$ & $40(3.3)$ & $97(8)$ & 1057 (86.7) & 13.3 \\
\hline
\end{tabular}

\section{Unwanted sexual attention and sexual coercion are} associated with victims' negative physical consequences

Table 3 shows the regression analysis output which reveals that four independent variables: unwanted attempts to establish a romantic relationship, unwanted attempts for sex, sexual stories and offensive sexual remarks had a statistically significant relationship with the variable measuring the magnitude of the negative physical consequences of sexual harassment $\left(R^{2}=36,8 \%, \mathrm{p}<0.01\right)$. These results show that mostly unwanted sexual attention and sexually coercive behaviours explain victims' negative physical consequences.

\section{Mental consequences and sexually harassing behaviours}

Table 4 shows that six independent variables: unwanted attempts to establish romantic sexual relationship, display of sexist material at work, unwanted attempts for sex, asks for dates despite refusal, crude and offensive sexist remarks, sex without consent had a statistically significant relationship with the variable measuring the magnitude of the negative mental consequences of sexual harassment $\left(R^{2}: 0.382, \mathrm{p}<0.01\right)$.

Job-related consequences and sexually harassing behaviours Job-related consequences

Table 5 illustrates that seven independent variables: retaliation for refusing to have sex, unwanted attempts for sex, unwanted attempts to kiss, unwanted sexual touches, sexual stories, ask for dates, threats of retaliation for not being sexually cooperative, had a statistically significant relationship with the variable measuring the magnitude of the job-related consequences of sexual harassment $\left(R^{2}: 0.452, \mathrm{p}<0,01\right)$. These results show that unwanted sexual attention and sexual coercion play a crucial role in the magnitude of job-related negative consequences for sexual harassment victims.

\section{DISCUSSION}

\section{Strengths and weaknesses in relation to other studies}

This study has found that 7 in 10 nurses have experienced sexual harassment at least once throughout their working lives. This is consistent with other studies that show that prevalence rates among female nurses are significantly high. ${ }^{727}$ Gender harassment is the most frequent type of sexual harassment, followed by unwanted sexual attention and sexual coercion. ${ }^{6}$ Private nurses are more likely to experience sexual harassment than public nurses. That is expected, provided that there are high power differences between nurses and physicians because they are simultaneously shareholders of the hospital. ${ }^{28}$ This study also shows that the age of female nurses is a significant factor in the frequency of sexual harassment as younger nurses and particularly those belonging to the age groups 18-30 years and $31-40$ years, more frequently experience sexual harassment compared with older nurses. This is consistent with other studies revealing the negative

\begin{tabular}{|c|c|c|c|c|c|}
\hline \multicolumn{4}{|c|}{ Outcome: negative physical consequences, score 1-5 (linear regression) } & \multicolumn{2}{|l|}{$95 \% \mathrm{Cl}$} \\
\hline Predictor variables in the model & Coef. & Std. error & $P$ value & Lower & Upper \\
\hline $\begin{array}{l}\text { Unwanted attempts to establish romantic } \\
\text { sexual relationship }\end{array}$ & 0.147 & 0.056 & $<0.001$ & -0.0147 & 0.0147 \\
\hline Display of sexist material at work & 0.156 & 0.054 & $<0.001$ & -0.0156 & 0.0156 \\
\hline Unwanted attempts for sex & 2.378 & 0.111 & $<0.001$ & -2.378 & 2.378 \\
\hline Sexual stories and jokes at work & 0.171 & 0.054 & $<0.001$ & -0.171 & 0.171 \\
\hline Crude and offensive sexual remarks & 0.153 & 0.065 & $<0.001$ & -0.153 & 0.153 \\
\hline (Constant) & 5.705 & 0.157 & $<0.001$ & -1.500 & 5.705 \\
\hline
\end{tabular}

$R^{2}: 0.368$ (adjusted $R^{2}: 0.342$ ) 
Table 4 Multiple regression analysis between sexual harassment behaviours and mental health outcomes

\begin{tabular}{|c|c|c|c|c|c|}
\hline \multicolumn{4}{|c|}{ Outcome: negative mental consequences, score 1-5 (linear regression) } & \multicolumn{2}{|l|}{$95 \% \mathrm{Cl}$} \\
\hline Predictor variables in the model & Coef. & Std. error & P value & Lower & Upper \\
\hline Unwanted attempts to establish romantic sexual relationship & 0.232 & 0.066 & $<0.001$ & -0.232 & 0.232 \\
\hline Unwanted attempts for sex & 0.462 & 0.107 & $<0.001$ & -0.462 & 0.462 \\
\hline Asks for dates despite refusal & 0.272 & 0.060 & $<0.001$ & -0.272 & 0.272 \\
\hline Crude and offensive sexist remarks & 0.207 & 0.057 & $<0.001$ & -0.207 & 0.207 \\
\hline Had sex with you without consent & 0.665 & 0.245 & $<0.001$ & -0.0665 & 0.665 \\
\hline (Constant) & 6.041 & 0.318 & $<0.001$ & -6.041 & 6.041 \\
\hline
\end{tabular}

$R^{2}: 0.382$ (Adjusted $\left.R^{2}: 0.363\right)$

relationship between age and frequency of sexual harassment and explicitly that younger women are more likely to face sexual harassment compared with their older counterparts. ${ }^{29} 30$ The marital status of nurses is another crucial factor of sexual harassment because unmarried and divorced nurses more frequently experience gender harassment and unwanted sexual attention behaviours, whereas divorced nurses more frequently face sexually coercive actions at work. ${ }^{31} 32$

This study is consistent with other studies that show that male doctors are the most common perpetrators and that harassers typically occupy senior positions. ${ }^{733}$ In most times, sexual harassment victims adopted passive coping strategies, whereas a considerable proportion decided to stay silent. ${ }^{143435}$ In the majority of times, no action was taken against the perpetrator showing that highly powerful wrongdoers are not penalised. ${ }^{20} 36$ As for the victims' decision to stay silent, the findings are consistent with the literature that suggests that victims' feelings of futility, fear of negative consequences and lack of organisational mechanisms are crucial factors that force victims to stay silent. ${ }^{37-40}$ Last, this study shows that all types of sexual harassment cause severe adverse physical, mental and job-related outcomes, while the more frequent these behaviours are, the more severe the consequences for the victims. $^{124142}$

\section{Strengths and limitations of the study}

This study has crucial strengths, such as the large and diverse sample of female nurses working in various contexts within the Greek health system. Moreover, this research study has shown the most frequent types of sexual harassment faced by nurses, along with their tendency to report/not report their experiences. Hence, it highlights crucial elements of the phenomenon in the health sector. However, this study has several considerations that need to be considered when interpreting its main findings. First, this is a cross-sectional study, not causality, but only associations between variables can be conducted. Second, only female nurses were analysed, and not male nurses or other health professionals leading to potential one-sided findings. Future studies should focus on answering the research questions in different working groups working in the healthcare industry. The low response rate of $20 \%$ can be a factor that may negatively influence the reliability of results, while the electronic format of the

\begin{tabular}{|c|c|c|c|c|c|}
\hline \multicolumn{4}{|c|}{ Outcome: negative job-related consequences, score 1-5 (linear regression) } & \multicolumn{2}{|l|}{$95 \% \mathrm{Cl}$} \\
\hline Predictor variables in the model & Coef. & Std. error & P value & Lower & Upper \\
\hline Treated you badly for refusing sex & 0.709 & 0.072 & $<0.001$ & -0.709 & 0.709 \\
\hline Unwanted attempts for sex & 0.503 & 0.112 & $<0.001$ & -0.503 & 0.503 \\
\hline Unwanted attempts to kiss & 0.309 & 0.074 & $<0.001$ & -0.309 & 0.309 \\
\hline Touched you in a sexual way & 0.265 & 0.076 & $<0.001$ & -0.265 & 0.265 \\
\hline Mistreated you because of your sex & 0.164 & 0.050 & $<0.001$ & & \\
\hline Display of sexual stories and jokes & 0.238 & 0.049 & $<0.001$ & -0.238 & 0.238 \\
\hline Ask for drinks despite refusal & 0.166 & 0.061 & $<0.001$ & -0.166 & 0.166 \\
\hline Feel threatened with retaliation for not being sexually cooperative & 0.184 & 0.074 & $<0.001$ & -0.184 & 0.184 \\
\hline (Constant) & 6.259 & 0.314 & $<0.001$ & -6.259 & 6.259 \\
\hline
\end{tabular}

$R^{2}: 0.452$ (Adjusted $R^{2}: 0.431$ ) 
questionnaire prevented those with no computer skills and internet to fill the questionnaire. Therefore, despite this study employing a large number of participants, the low response rate might lead to conclusions that are not representative of the female Greek nurses population.

\section{CONCLUSIONS AND POLICY IMPLICATIONS}

We now focus on discussing the political and managerial implications of this research article. The findings demonstrate that sexual harassment is a high-frequency phenomenon for female nurses working in the Greek NHS; hence immediate measures should be implemented to reduce the pervasiveness of the issue in clinical practice. Health managers are requested to alter how public and private hospitals deal with sexual harassment and empower victims to report it. The main finding of this study is that victims do not report their experiences because of the lack of organisational mechanisms to capture their voices and the fear of negative consequences (being labelled negatively, losing their jobs). An effective approach would be establishing anonymous and transparent communication channels through which victims could safely voice their discontent. ${ }^{43}$ Moreover, another reason for victims not reporting sexual harassment is that highly powerful perpetrators are not penalised in most cases, thus, stimulating victims' beliefs that speaking up is futile. Therefore, creating an independent external committee responsible for conducting internal investigations and that would have the legitimacy to impose sanctions on wrongdoers is crucial to nurture a culture of justice in the organisation. ${ }^{44}$ Furthermore, the results of this research paper have shown that public hospitals lack well-defined organisational policies against sexual harassment. Human resource management professionals should introduce zero-tolerance organisational policies against harassment at work that would be included in the staff handbook. ${ }^{44-46}$ Additionally, the running of regular campaigns with the participation of cross-functional teams to inform and train workers on how to prevent sexual harassment is another step against sexual harassment as described in detail previously. ${ }^{47}$ Last but not least, any effective policy against sexual harassment requires a monitoring mechanism through which health managers should assess the efficacy of the implemented policies in the workplace. ${ }^{45-47}$ Explicitly, this tool would reveal how well the organisation is performing towards decreasing the frequency of sexual harassment and benefit from employees' novel recommendations on how to eliminate sexual harassment.

Acknowledgements The authors thank the female nurses who completed this survey and the Hellenic Nurse Association who helped to distribute the survey for their support.

Contributors PP conceived and designed the study. He also collected, analysed and wrote the draft of the manuscript. PP is responsible for the overall content as the guarantor.

Funding The authors have not declared a specific grant for this research from any funding agency in the public, commercial or not-for-profit sectors.

Competing interests None declared.
Patient consent for publication Not required.

Ethics approval The Humanities \& Social Sciences Research Ethics Committee (HSSREC) of Warwick University approved the study (E-645-01-20). Consent was obtained through a consent statement at the start of the survey, which asked participants to give their permission for their data to be used for research purposes and click on 'I give my consent to proceed with the survey. Data were carefully analysed to ensure the anonymity, privacy and confidentiality of the participant nurses, thus protecting them from any potential harm or further intrusion.

Provenance and peer review Not commissioned; externally peer reviewed.

Data availability statement Data are available upon reasonable request.

Supplemental material This content has been supplied by the author(s). It has not been vetted by BMJ Publishing Group Limited (BMJ) and may not have been peer-reviewed. Any opinions or recommendations discussed are solely those of the author(s) and are not endorsed by BMJ. BMJ disclaims all liability and responsibility arising from any reliance placed on the content. Where the content includes any translated material, BMJ does not warrant the accuracy and reliability of the translations (including but not limited to local regulations, clinical guidelines, terminology, drug names and drug dosages), and is not responsible for any error and/or omissions arising from translation and adaptation or otherwise.

Open access This is an open access article distributed in accordance with the Creative Commons Attribution Non Commercial (CC BY-NC 4.0) license, which permits others to distribute, remix, adapt, build upon this work non-commercially, and license their derivative works on different terms, provided the original work is properly cited, appropriate credit is given, any changes made indicated, and the use is non-commercial. See: http://creativecommons.org/licenses/by-nc/4.0/.

ORCID iD

Panagiotis Papantoniou http://orcid.org/0000-0001-5384-4918

\section{REFERENCES}

1 Magnusson Hanson LL, Nyberg A, Mittendorfer-Rutz E, et al. Work related sexual harassment and risk of suicide and suicide attempts: prospective cohort study. BMJ 2020;370:m2984.

2 U.S. Equal Employment Opportunity Commission. Facts about sexual harassment. U.S. Equal Employment Opportunity Commission, 2010.

3 Fitzgerald LF, Shullman SL, Bailey N, et al. The incidence and dimensions of sexual harassment in academia and the workplace. $J$ Vocat Behav 1988;32:152-75.

4 Latcheva R. Sexual harassment in the European Union: a pervasive but still hidden form of gender-based violence. $J$ Interpers Violence 2017;32:1821-52.

5 UN Women. Facts and figures: ending violence against women. UN Women, 2016.

6 Hahn S, Hantikainen V, Needham I, et al. Patient and visitor violence in the General Hospital, occurrence, staff interventions and consequences: a cross-sectional survey. J Adv Nurs 2012;68:2685-99.

7 Kahsay WG, Negarandeh R, Dehghan Nayeri N, et al. Sexual harassment against female nurses: a systematic review. BMC Nurs 2020;19:58.

8 Fafliora E, Bampalis VG, Zarlas G, et al. Workplace violence against nurses in three different Greek healthcare settings. Work 2016;53:551-60.

9 Cogin JA, Fish A. An empirical investigation of sexual harassment and work engagement: surprising differences between men and women. J Manag Organ 2009;15:47-61.

10 Valente SM, Bullough V. Sexual harassment of nurses in the workplace. J Nurs Care Qual 2004;19:234-41.

11 Hibino Y, Hitomi Y, Kambayashi Y, et al. Exploring factors associated with the incidence of sexual harassment of hospital nurses by patients. J Nurs Scholarsh 2009;41:124-31.

12 Willness CR, Steel P, LEE K. A meta-analysis of the antecedents and consequences of workplace sexual harassment. Pers Psychol 2007:60:127-62.

13 Holland KJ, Cortina LM. Sexual harassment: undermining the wellbeing of working women. In: Handbook on well-being of working women, 2016.

14 Cortina LM, Berdahl JL. Sexual harassment in organizations: A decade of research in review. In: The SAGE Handbook of organizational behavior. Volume I. Micro Approaches, 2008.

15 Magnavita N, Heponiemi T. Violence towards health care workers in a public health care facility in Italy: a repeated cross-sectional study. BMC Health Serv Res 2012;12:108. 
16 McLaughlin H, Uggen C, Blackstone A. Sexual harassment, workplace authority, and the paradox of power. Am Sociol Rev 2012;77:625-47.

17 Rabelo VC, Cortina LM. Two sides of the same coin: gender harassment and heterosexist harassment in LGBQ work lives. Law Hum Behav 2014;38:378-91.

18 Camerino D, Estryn-Behar M, Conway PM, et al. Work-Related factors and violence among nursing staff in the European next study: a longitudinal cohort study. Int J Nurs Stud 2008;45:35-50.

19 McDonald P, Charlesworth S. Workplace sexual harassment at the margins. Work Employ Soc 2016;30:118-34.

20 McDonald P. Workplace sexual harassment 30 years on: a review of the literature. International Journal of Management Reviews 2012;14:1-17.

21 Spector PE, Zhou ZE, Che XX. Nurse exposure to physical and nonphysical violence, bullying, and sexual harassment: a quantitative review. Int J Nurs Stud 2014;51:72-84.

22 Zhang L, Wang A, Xie X, et al. Workplace violence against nurses: a cross-sectional study. Int J Nurs Stud 2017;72:8-14.

23 Tollstern Landin T, Melin T, Mark Kimaka V, et al. Sexual harassment in clinical Practice-A cross-sectional study among nurses and nursing students in sub-Saharan Africa. SAGE Open Nurs 2020;6:237796082096376.

24 Sánchez-Fernández J, Muñoz-Leiva F, Montoro-Ríos FJ. Improving retention rate and response quality in web-based surveys. Comput Human Behav 2012;28:507-14

25 Gutek BA, Murphy RO, Douma B. A review and critique of the sexual experiences questionnaire (seq). Law Hum Behav 2004;28:457-82.

26 Streiner DL, Norman GR. Health measurement scales: a practical guide to their development and use. health measurement scales: a practical guide to their development and use, 2008.

27 Lu L, Dong M, Lok GKI, et al. Worldwide prevalence of sexual harassment towards nurses: a comprehensive meta-analysis of observational studies. J Adv Nurs 2020;76:980-90.

28 Pina A, Gannon TA, Saunders B. An overview of the literature on sexual harassment: perpetrator, theory, and treatment issues. Aggress Violent Behav 2009;14:126-38.

29 Reese LA, Lindenberg KE. Gender, age, and sexual harassment. Rev Public Pers Adm 2005;25:325-52.

30 Ohse DM, Stockdale MS. Age comparisons in workplace sexual harassment perceptions. Sex Roles 2008;59:240-53.

31 Merkin RS. Sexual harassment indicators: the Socio-Cultural and cultural impact of marital status, age, education, race, and sex in Latin America. Intercult Commun Stud 2012
32 Berdahl JL. The sexual harassment of uppity women. J Appl Psychol 2007:92:425-37.

33 Strauss S. Overview and summary: sexual harassment in healthcare. Online J Issues Nurs 2019;24.

34 Chawla N, Gabriel AS, O'Leary Kelly A, et al. From \#MeToo to \#TimesUp: Identifying Next Steps in Sexual Harassment Research in the Organizational Sciences. J Manage 2021;47:551-66.

35 Bondestam F, Lundqvist M. Sexual harassment in higher education - a systematic review. Eur J High Higher Education 2020;10:397-419.

36 Cummings KM, Armenta M. Penalties for peer sexual harassment in an academic context: the influence of harasser gender, participant gender, severity of harassment, and the presence of bystanders. Sex Roles 2002;47:273-80.

37 Morrison EW, Wheeler-Smith SL, Kamdar D. Speaking up in groups: a cross-level study of group voice climate and voice. J Appl Psychol 2011;96:183-91.

38 Morrison EW. Employee voice and silence. annual review of organizational psychology and organizational behavior, 2014.

39 Weiss M, Morrison EW. Speaking up and moving up: How voice can enhance employees' social status. J Organ Behav 2019;40:5-19.

$40 \mathrm{Knoll} \mathrm{M}$, Hall RJ, Weigelt $\mathrm{O}$. A longitudinal study of the relationships between four differentially motivated forms of employee silence and burnout. J Occup Health Psychol 2019;24:572-89.

41 Burn SM. The psychology of sexual harassment. Teach Psychol 2019;46:96-103.

42 Pina A, Gannon TA. An overview of the literature on antecedents, perceptions and behavioural consequences of sexual harassment. $J$ Sex Aggress 2012;18:209-32.

43 Sojo VE, Wood RE, Genat AE. Harmful Workplace Experiences and Women's Occupational Well-Being: A Meta-Analysis. Psychol Women Q 2016;40:10-40.

44 Fitzgerald LF. Still the last great open secret: sexual harassment as systemic trauma. J Trauma Dissociation 2017;18:1-7.

45 Fernando D, Prasad A. Sex-based harassment and organizational silencing: how women are led to reluctant acquiescence in academia. Human Relations 2019;72:1565-94.

46 Hershcovis MS, Parker SK, Reich TC. The moderating effect of equal opportunity support and confidence in grievance procedures on sexual harassment from different perpetrators. J Bus Ethics 2010;92:415-32.

47 Papantoniou P. Are male nurses sexually harassed? A crosssectional study in the Greek health system. BMC Nurs 2021;20:1-9. 